Supplement of

\title{
Isotopic composition of daily precipitation along the southern foothills of the Himalayas: impact of marine and continental sources of atmospheric moisture
}

\section{Ghulam Jeelani et al.}

Correspondence to: Ghulam Jeelani (geojeelani@gmail.com)

The copyright of individual parts of the supplement might differ from the CC BY 4.0 License. 


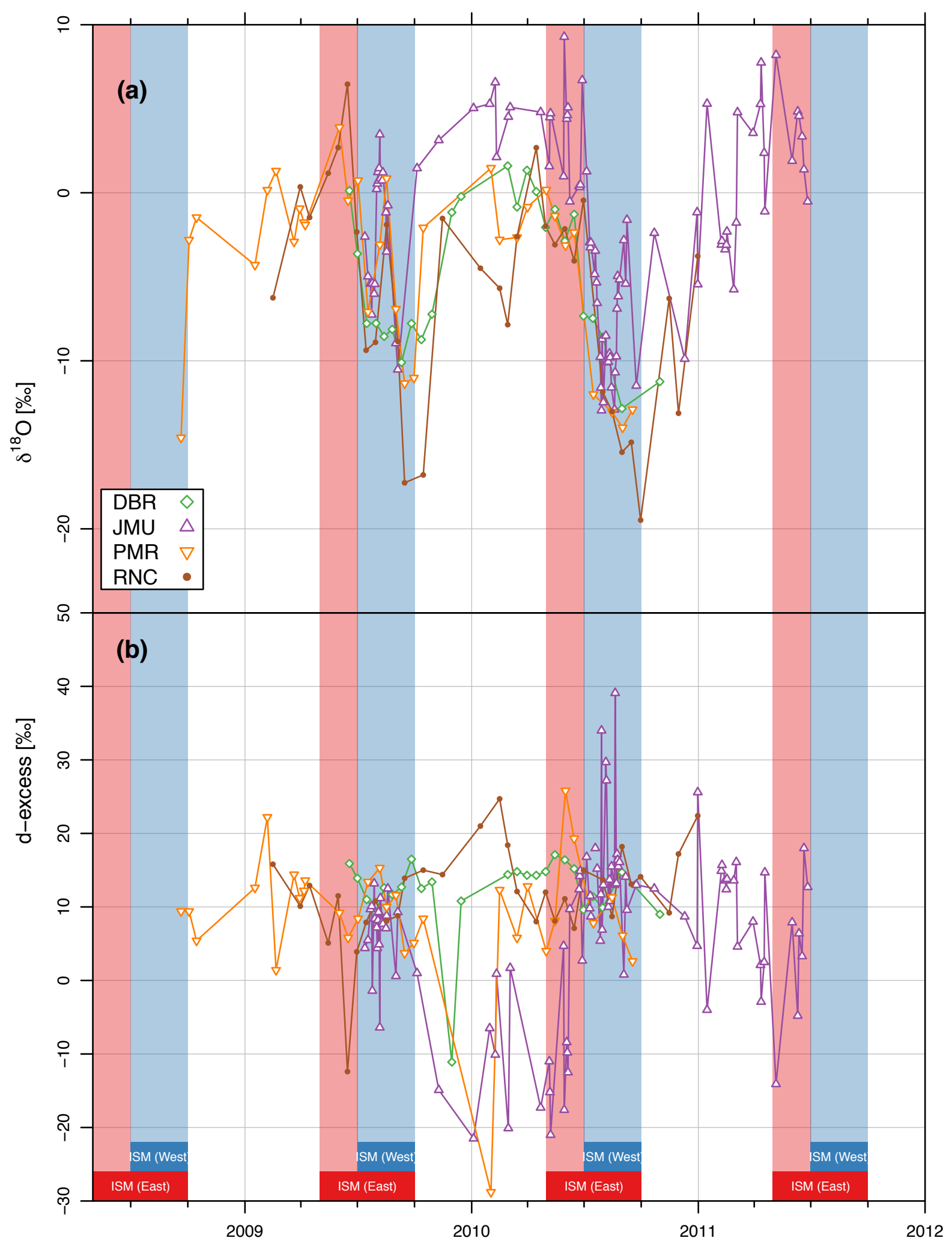

Figure S1. Seasonal variations of $\delta^{18} \mathrm{O}(\mathrm{a})$ and d-excess (b) of daily rainfall collected at four stations (Jammu -JMU; Palampur - PMR; Ranichauri - RNC; Dibrugarh - DBR) collecting daily rainfall samples along southern foothills of the Himalayas (cf. Fig.1); for other two stations (Srinagar - SGR and Jorhat - JRH) please refer Fig. 3 of the manuscript. Duration of 
Indian Summer Monsoon (ISM) period is marked by blue (Jammu, Palampur: JulySeptember) and red (Dibrugarh: May-September) shading. Duration of ISM period at Ranichauri: June-September.

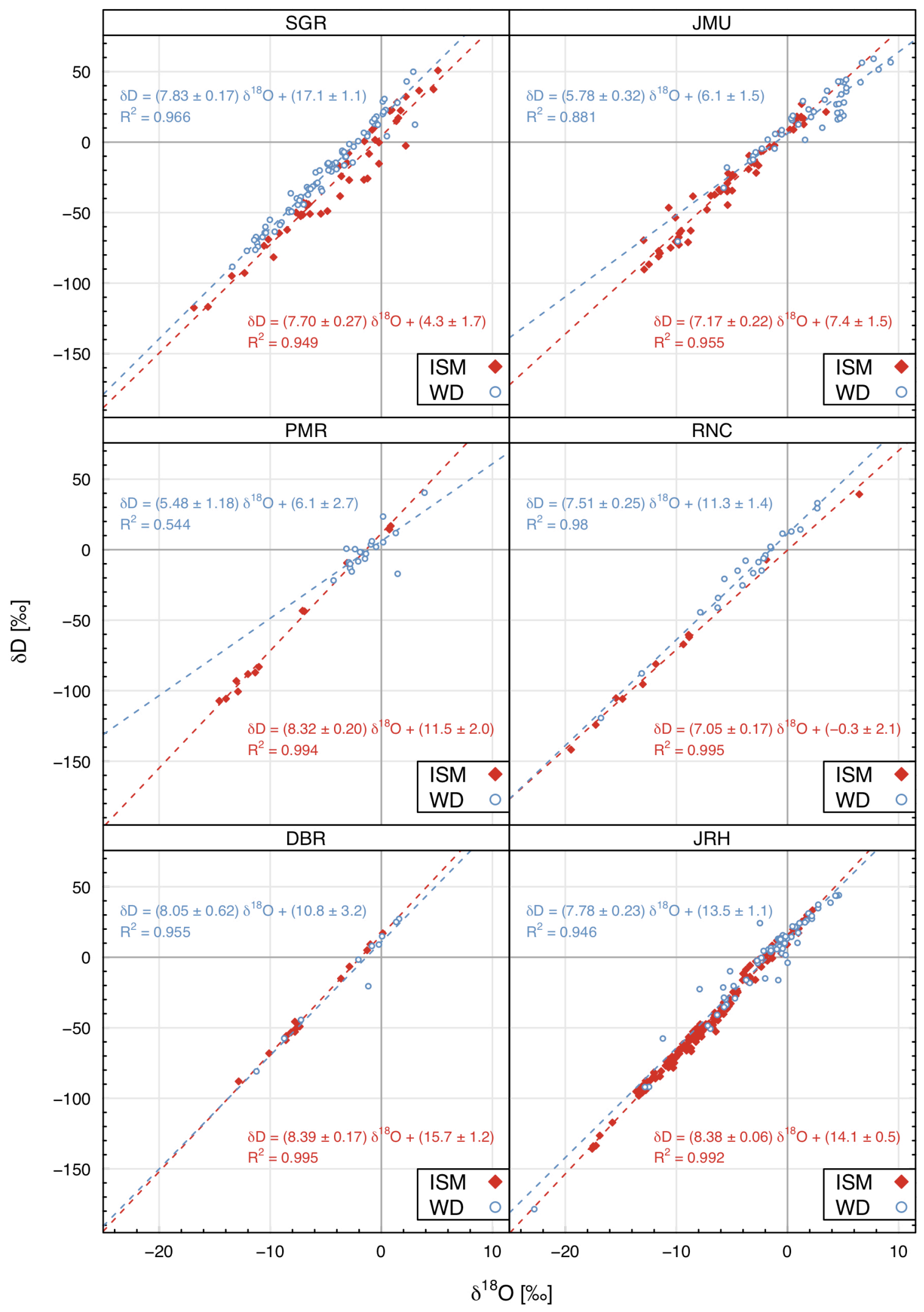


Figure S2. $\delta^{2} \mathrm{H}-\delta^{18} \mathrm{O}$ relationship for isotope data gathered by six stations (Srinagar - SGR; Jammu -JMU; Palampur - PMR; Ranichauri - RNC; Jorhat - JRH; Dibrugarh - DBR) collecting daily rainfall samples along southern foothills of the Himalayas (cf. Fig.1). Local Meteoric Water Lines were calculated separately for Indian Summer Monsoon (ISM) and Western Disturbances (WD) periods (see caption of Fig. S1).
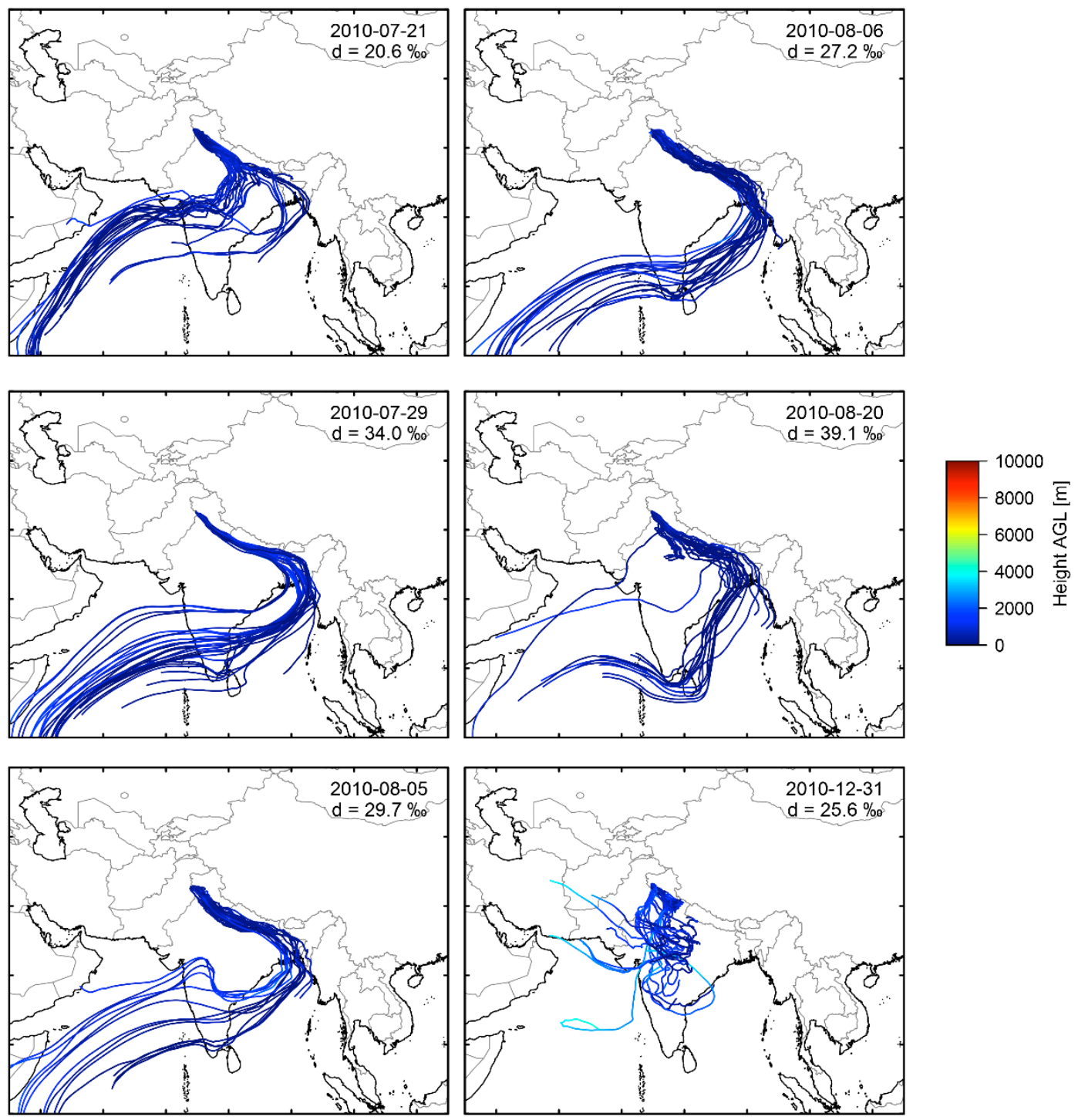

Figure S3. Ensembles of 10-day backward trajectories calculated for daily rainfall samples collected at Jammu station (cf. Fig.1) showing high values of deuterium excess $(>20 \%$ o). Colour scale indicates elevation above the ground level in meters. 

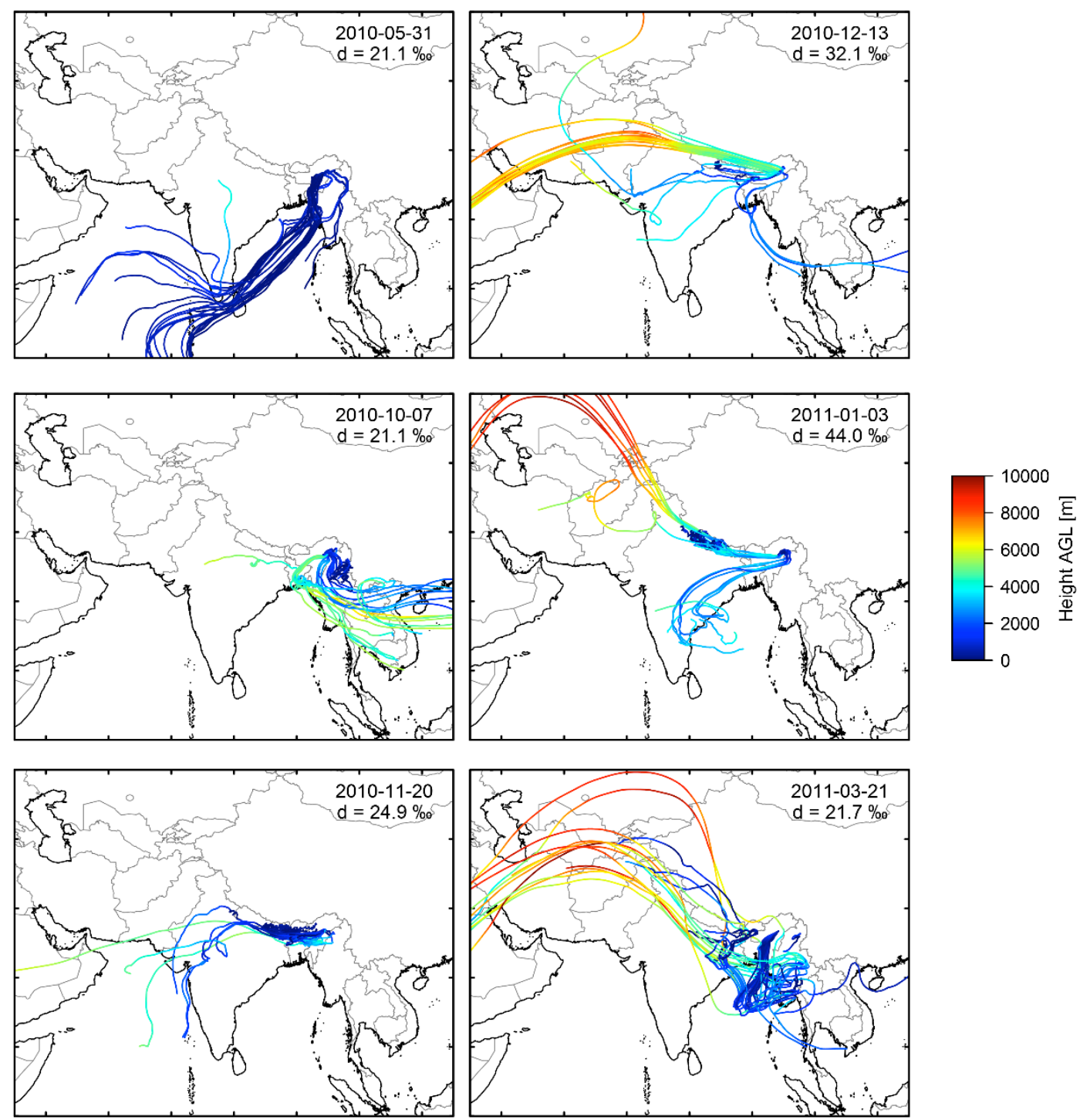

Figure S4. Ensembles of 10-day backward trajectories calculated for daily rainfall samples collected at Jorhat station (cf. Fig.1), showing high values of deuterium excess ( $>20 \%$ ). Colour scale indicates elevation above the ground level in meters. 